\begin{tabular}{r|l|l|l}
$\begin{array}{c}\text { Case Reports in } \\
\text { Gastroenterology }\end{array}$ & $\begin{array}{l}\text { Case Rep Gastroenterol 2011;5:52-55 } \\
\text { DOl: 10.1159/000322938 }\end{array}$ & $\begin{array}{l}\text { Published online: } \\
\text { January 14, 2011 }\end{array}$ & $\begin{array}{l}\text { O 2011 S. Karger AG, Basel } \\
\text { ISSN 1662-0631 } \\
\text { www.karger.com/crg }\end{array}$ \\
\hline
\end{tabular}

\title{
Does Phenytoin Improve the Healing of Gastrointestinal Fistulas?
}

\author{
Saed Jaber Zuhair Rihy Rafaeil Joseph \\ Mohammad Al-Khayat \\ Department of Surgery, King Fahd Military Medical Complex, Dhahran, \\ Saudi Arabia
}

\section{Key Words}

Pancreatic fistula · Phenytoin · Colocutaneous fistula - Whipple surgery · Fibrosis

\begin{abstract}
Pancreatic fistulas are among the most devastating complications after pancreatic surgery. Their subsequent development can be lethal. We report two cases of pancreatic fistulas treated with phenytoin. Fistula tract healing consists of several processes, including cell migration and the formation of a new extracellular matrix. Multiple studies have shown that phenytoin can promote wound healing and induce faster fibrosis. We postulate that such a positive effect can be used to enhance fibrosis of the pancreatic fistula tract. We treated two patients who had developed high-output pancreatic fistulas after pancreatic surgery. The first underwent hand-assisted laparoscopic pancreatic necrosectomy and developed two high-output pancreatic fistulas and a colocutaneous fistula. The second occurred post Whipple surgery. Both were given oral phenytoin after failure to respond to other measures. In conclusion, oral phenytoin may have a positive effect in the treatment of fistulas. Prospective studies are needed to indicate this possible effect of phenytoin on fistula healing.
\end{abstract}

\section{Introduction}

Pancreatic fistulas are a heterogeneous group of disorders in which both disruption of the pancreatic dust and leakage of amylase and lipase-rich fluid to the skin are present. The most common etiology is post pancreatic surgery. Pancreatic fistula incidence is $20 \%$ after Whipple procedure, $30 \%$ after distal pancreatectomy, and $40 \%$ after pancreatic necrosectomy. Previously, pancreatic fistulas were managed through re-operation, which was associated with a high mortality rate. Extensive effort has been applied to the management of patients with pancreatic fistulas in order to decrease the morbidity and mortality associated to this type of fistula. That included improving the nutritional status 


\begin{tabular}{r|l|l|l}
$\begin{array}{r}\text { Case Reports in } \\
\text { Gastruanteriology }\end{array}$ & $\begin{array}{l}\text { Case Rep Gastroenterol 2011;5:52-55 } \\
\text { DOI: 10.1159/000322938 }\end{array}$ & $\begin{array}{l}\text { Published online: } \\
\text { January 14, 2011 }\end{array}$ & $\begin{array}{l}\text { O 2011 S. Karger AG, Basel } \\
\text { ISSN 1662-0631 } \\
\text { www.karger.com/crg }\end{array}$ \\
\hline
\end{tabular}

of patients and treating any underlying disorders that prevented the fistulas from healing. Somatostatin is also used to enhance the process of fistula healing and to shorten the period required for closure. Previous studies have confirmed the ability of phenytoin to promote wound healing [1]. We report that the use of phenytoin enhances the closure of pancreatic fistulas by presenting two cases who underwent pancreatic surgery complicated with the development of a high-output fistula.

\section{Case Reports}

A 49-year-old male patient presented with diffuse abdominal pain, fever and jaundice. A computed tomography scan of the abdomen showed an extensive picture of necrotizing pancreatitis. Fine-needle aspiration was performed and proved the presence of infected necrotizing pancreatitis. The patient was taken to surgery, and a hand-assisted pancreatic necrosectomy was performed. Intraoperatively, three Duval sump drains were inserted, one at the head of the pancreas, another at the tail of the pancreas, and the last in the lesser sac, overlying the body of the pancreas. Postoperatively, the patient developed a high-output pancreatic fistula from all of the drains. The patient was started on Sandostatin on the first postoperative day, however, the drainage amount was still high in spite of the high dose of Sandostatin at $600 \mu \mathrm{g} /$ day. The drain at the head was draining pancreatic fluid at around $400 \mathrm{ml} /$ day, the drain at the tail of the pancreas was draining $150 \mathrm{ml} /$ day, and on the tenth postoperative day, a controlled colocutaneous fistula also developed throughout the lesser sac drain. The amount of output was $100 \mathrm{ml} /$ day of feculent material from a fistula that was found to originate from the transverse colon as diagnosed by a fistulogram. When two weeks of treatment with Sandostatin showed minimal effect, we decided to start the patient on oral phenytoin at $300 \mathrm{mg}$ /day through a nasogastric tube. Four days later there was a significant drop in the output of all drains. Ten days later, the pancreatic fistula at the tail of the pancreas and the colocutaneous fistula at the head both closed after all of these drains had been slowly extracted. One month after surgery, the patient recovered and was discharged home.

The second case was a 53-year-old male patient who underwent Whipple procedure for a pancreatic adenocarcinoma. Postoperatively, the patient developed a high-output pancreatic fistula from the pancreatic-jejunal anastomosis. Sandostatin was started with no significant reduction in fistula output after ten days of treatment. We started oral phenytoin at a dose of $300 \mathrm{mg} /$ day. Five days later there was a significant drop in fistula output. Unfortunately, the patient developed neutropenia, so phenytoin was stopped. However, the amount of fistula output dropped from 300 to $40 \mathrm{ml} /$ day. The pancreatic fistula continued to close up gradually afterward. Unfortunately, the patient developed significantly delayed gastric emptying that required him to have a prolonged hospitalization.

\section{Discussion}

The safety of pancreatic surgery has increased in recent years. In spite of the decrease in mortality after pancreatic surgery, morbidity is still ranging from 10 to $50 \%$. One of the most common complications of pancreatic surgery is pancreatic fistula. The overall incidence of pancreatic fistulas after Whipple procedure is about $20 \%$. In distal pancreatectomy, the incidence reaches up to $30 \%$, whereas with pancreatic necrosectomy, the incidence is around $50 \%$. The consequences can be life-threatening (i.e., bleeding, pancreatic fluid collection, abscesses) and cause prolongation of hospital stay and an increase in costs.

Abdominal computed tomography is considered the initial study of choice for evaluating and assessing intra-abdominal postoperative conditions. In order to evaluate the status of the pancreatic duct, secretin-enhanced magnetic resonance pancreatography is considered the study of choice, as it also allows us to precisely locate the disruption without any risk of infection due to the external injection of contrast in fistulography. 
The treatment of fistulas requires multiple therapeutic modalities, which include conservative parameters as well as radiological, endoscopic, and surgical treatments. Conservative measures usually include parenteral or enteral nutritional support and the use of Somatostatin. Such a treatment will take anywhere from 4 to 18 weeks for the fistula to close, resulting in closure of the fistula in nearly $85 \%$ of cases. Percutaneous embolization of the pancreatic duct with different sclerosing agents is a new method that can help facilitate the closure of fistulas in a short period of time. The sclerosing agents used are prolamine, fibrin glue, neoprene, and n-butyl cyanoacrylate. If there is incomplete disruption of the pancreatic duct, endoscopic stenting of the pancreatic duct can allow healing of the fistula. The use of transpapillary stents allows the surgeon to bypass the high resistance of the sphincter of Oddi and ductal strictures, while subsequently reducing the intraductal pressure and the driving force behind the fistula. All of the modalities mentioned above depend on allowing the tract to fibrose and eventually close by decreasing the output of pancreatic secretion into the tract. The process of tract healing depends on the growth of connective tissue, which will promote closure of the fistula.

A frequently observed and undesirable side effect of phenytoin is gingival hyperplasia [1]. This side effect results from the growth of connective tissue. Multiple medical reports have promoted the use of phenytoin to enhance wound healing $[2,3]$. The mechanism by which phenytoin promotes wound healing is not fully understood, however, several theories have been proposed. The mechanism by which phenytoin induces wound healing includes stimulation of fibroblast proliferation, enhancing the formation of granulation tissue, decreasing collagenase activity, and inhibition of glucocorticoid activity as well as direct and indirect antibacterial activity by affecting inflammatory cells and neovascularization $[4,5]$. There is also evidence that phenytoin may play a role in anastomotic healing $[6,7]$.

Based on such evidence, we used phenytoin in two cases with pancreatic fistulas. The fistulas in both patients closed within a short period of time. The use of Somatostatin in both cases showed no decrease in the output of the fistula; however, after four days of using phenytoin, there was a significant decrease in fistula output. Of course, it is difficult to prove such an effect from phenytoin alone, but having a rapid response in terms of closure cannot be attributed to the other conservative techniques that we used, such as nutritional support and Somatostatin. The ability of phenytoin to promote closure of fistulas seems promising if we can prove its effect, but this will require further trials.

In conclusion, the effect of phenytoin on healing has been proven in pilonidal sinus wounds, and such a positive effect on healing can be applied on gastrointestinal fistula healing. Further prospective trials are needed to evaluate such an effect. 


\section{References}

1 Bhatia A, Prakash S: Topical phenytoin for wound healing. Dermatol Online J 2004;10:5.

2 Johnson TJ: Use of topical phenytoin for wound care. S D J Med 1998;51:387-388.

-3 Pereira CA, Alchorne Ade O: Assessment of the effect of phenytoin on cutaneous healing from excision of melanocytic nevi on the face and on the back. BMC Dermatol 2010;10:7.

4 Flanagan PM, Flanagan AM: Phenytoin and wound healing. Trop Doct 1992;22:172.

5 El-Nahas M, Gawish H, Tarshopy M: The impact of topical phenytoin on recalcitrant neuropathic diabetic foot ulceration. J Wound Care 2009;15:321-327.

-6 Günes HV, Demirer S, Aydinuraz K, Kepenekci I, Kuterdem E, Aribal D: Effects of basic fibroblast growth factor and phenytoin on healing of abdominal wall fascia and colonic anastomoses. Int Surg 2006;91:151-156.

7 Turan M, Saraydin SU, Canbay E, Karadayi K, Bulut E, Cetinkaya O, Elagöz S, Sen M: Positive effects of phenytoin on experimental colonic anastomoses. Int J Colorectal Dis 2004;19:250-257. 